\title{
İşletme Kuluçkalarında Firmalar Arası Ağbağlaşma Faaliyetlerinin Yeni Kurulan Firmaların Hayatta Kalabilirliği Üzerine Etkisi
}

\author{
The Effect of Inter-Firm Networking Activities in Business Incubators on Newly Founded \\ Firms' Survival
}

Onur SUNGUR ${ }^{1}$

\begin{abstract}
ÖZET
Işletme kuluçkaları uygulamaları, çeşitli destekleyici hizmetler sayesinde yeni kurulan firmaların hayatta kalabilirlik oranlarını arttırmayı amaçlayan uygulamalardır. Bu hizmetlerden birisi de aracılık/ağbağlaşma faaliyetleridir. Kiracı firmalar arasındaki işbirliği ve ağbağlaşmanın, hayatta kalma olasılığı üzerinde önemli etkisi olmaktadır. Bu çalışmada, Türkiye'de de işletme kuluçkaları olarak uygulanmakta olan İş Geliştirme Merkezleri'nde (işGEM) kiracı firmalar arasındaki işbirliği ve ağbağlaşma faaliyetlerinin hayatta kalma üzerindeki etkisi araştırılmıştır. Çalışma sonucunda, işbirliği içerisinde olan firmalar ile işbirliği içerisinde olmayan firmaların hayatta kalma olasılıkları arasında önemli farklılıklar olduğu sonucuna ulaşılmıştır.
\end{abstract}

Anahtar Kelimeler: iş̧letme kuluçkaları, iş geliştirme merkezleri, ağbağlaşma, hayatta kalma analizi

\section{GíRiş}

Yeni kurulan firmaların büyüme ve hayatta kalmasını sağlamaya yönelik pek çok destek mekanizması bulunmaktadır. Bunlardan birisi de dünyada uzun yıllardır uygulanmakta olan ve son zamanlarda Türkiye'de de giderek yaygınlaşmaya başlayan "işletme kuluçkaları" (business incubator) uygulamalarıdır. İşletme kuluçkası kavramı, genç firmalara fiziksel çalışma alanı, yönetim desteği, finansman erişimi, teknik ve diğer destekleyici hizmetlerin sunulduğu ve onların başlangıç aşamaları boyunca hayatta kalmaları ve büyümeleri için yardımcı olan kurumları ifade eden geniş bir kavramdır (Suk ve Mooweon, 2006: 30). İşletme kuluçkaları uygulamalarında, yeni kurulan girişimlere fiziksel altyapıya erişim, ofis desteği, başlangıç sermayesi, finansal kaynaklara erişim, danışmanlık destekleri ve ağbağlaşma (networking) hizmetleri gibi pek çok hizmet sunulmakta ve böylelikle zorlu başlangıç yıllarını başarıyla tamamlamaları amaçlanmaktadır.

\begin{abstract}
Business incubators are programs that aim to increase the survival rates of newly established firms through various supporting services. One of these services is networking activities. Cooperation and networking between tenant firms have significant effects on the probability of survival. In this study, the effects of networking and collaboration activities between tenants firm on firm survival is examined through the lenses of Business Development Centers (ISGEMs). As a result of the study, it is concluded that there is a significant difference between collaborating firms and non-collaborating firms in terms of their survival rates.
\end{abstract}

Keywords: Business incubators, business development centers (ISGEMS), networking, survival analysis

Girişimcilik sürecinde ağbağlaşma yaklaşımının önemi literatürde pek çok çalışmada vurgulanmaktadır (Birley, 1985; Powell vd., 1996; Powell vd., 2005; Gay ve Dousset, 2005; McAdam vd., 2006). Bununla birlikte, işletme kuluçkalarının yeni kurulan firmalar açısından yararlarını ele alan pek çok çalışma bulunmakla birlikte, ağbağlaşmayı kolaylaştırıcı bir mekanizma olarak işletme kuluçkalarında ağbağlaşma konusunu ele alan çalışma sayısı oldukça azdır (McAdam ve Marlow, 2008: 220). Firmaların, diğer firmalarla işbirliği ve ağbağlaşma faaliyetlerinde bulunması, kaynaklara, bilgiye, tedarikçilere, müşterilere ve pazarlara ulaşmasını kolaylaştırmakta ve yenilikçiliği teşvik etmektedir. Ağbağlaşma faaliyetlerinin önemi, yeni kurulan firmalar için daha da önem arz etmektedir. Çünkü yeni kurulan firmalar, henüz başlangıç yıllarında bu kaynaklara erişim imkanına sahip değillerdir. Dolayısıyla, yeni kurulan firmalar açısından işbirliği ve ağbağlaşma faaliyetlerinin, hem büyüme hem de hayatta kalma açısından pozitif etkileri bulunmaktadır (Granovetter, 1985; Larson ve Starr, 1993; Gulati, 
1999; Havnes ve Senneseth, 2001; Andersson vd., 2002; Zaheer ve Bell, 2005). Ağbağlar üzerine yapılan pek çok çalışmada, bu tür sosyal ve girişimsel ağların firma büyüme ve hayatta kalması için kritik faktörler olduğu vurgulanmaktadır (Uzzi, 1996; 684-695). Ağbağlaşma faaliyetleri, ağbağ kaynakları ve ağbağ desteği yeni firmaların kuruluş sürecinde önemli unsurlar olmaktadır (Johannisson, 1988; Hansen vd., 2000; Freel, 2003; Rothschild ve Darr, 2005).

Bu kapsamda, çalışmanın amacı, işletme kuluçkalarında yer alan firmaların birbirleriyle olan işbirliği ve ağbağlaşma faaliyetlerinin yeni kurulan girişimlerin hayatta kalma olasılığı üzerindeki etkisinin araştırılmasıdır. Literatürde işletme kuluçkalarının firmaların birbirleriyle işbirliği yapmasını ve ağbağlaşmayı teşvik ettiği ve bu sayede ağbağlaşma içerisinde olan firmaların ağbağlaşma içerisinde olmayan firmalara göre hayatta kalma olasılıklarının arttığı vurgulanmaktadır. Bu çalışma, bu teoriyi test etmeyi amaçlamaktadır.

Çalışma, teorik çerçeve itibariyle firma teorisi, hayatta kalma, işletme kuluçkaları, ağbağlaşma teorisi gibi pek çok konuyu kapsamakla birlikte, temel olarak işletme kuluçkalarının ağbağlaşma hizmeti sayesinde firmaların hayatta kalma olasılıklarını arttırıp artırmadığı sorusuna cevap aramaktadır. Bu nedenle çalışmanın kavramsal çerçevesi işletme kuluçkaları ve özelde de işletme kuluçkalarında ağbağlaşma konuları üzerine odaklanmaktadır. Bununla birlikte, uygu- lama kısmını oluşturan firma teorisi ve hayatta kalma analizine çalışmanın kapsamını aştığı için ayrıntısıyla girilmemektedir.

\section{IŞLETME KULUÇKALARI KAVRAMI}

Işletme kuluçkası kavramına yönelik literatürde pek çok çalışma ve tanımlama bulunmaktadır (Phan, Siegel ve Wright, 2005: 169; UN, 2009: 74; Winger, 2000: 12; Brooks, 1986: 24; Lumpkin ve Ireland, 1988: 61; Peters, Rice ve Sundararajan, 2004: 83; Grimaldi ve Grandi, 2005: 111; Allen ve Rahman, 1985: 12). Genel olarak işletme kuluçkası kavramı, herhangi bir şekilde girişimcilere fikirlerinin başlangıç aşamasından yeni girişimin kuruluşuna kadar olan süreçte yardımcı olan kuruluşları kapsayan geniş bir tanım olarak da kullanılmaktadır. Dolayısıyla; bu geniş tanım; bir tarafta teknokentleri ve bilim parklarını, diğer tarafta da herhangi bir fiziksel konumu bulunmayan ve bunun yerine girişim destek hizmetleri ağbağı sunan yapılanmaları da (duvarsız kuluçkaları da) kapsamaktadır (Adegbite, 2001: 158).

Kuluçka literatüründe, çok detaylı ve pek çok açıdan birbirine benzeyen farklı kuluçka tanımlamaları yer almaktadır. Ancak yapılan tanımlamalara bakıldığında; tüm kuluçka tanımlamalarında 4 unsurun özellikle vurgulandığı dikkati çekmektedir. Bunlar (Bergek ve Norrman (2008: 21); (1) Paylaşılan ofis alanı, (2) Ortak destekleyici hizmetler havuzu, (3) Profesyonel işletme desteği ve danışmanlık ve (4) İçsel ve dışsal ağbağlaşma sağlanmasıdır.

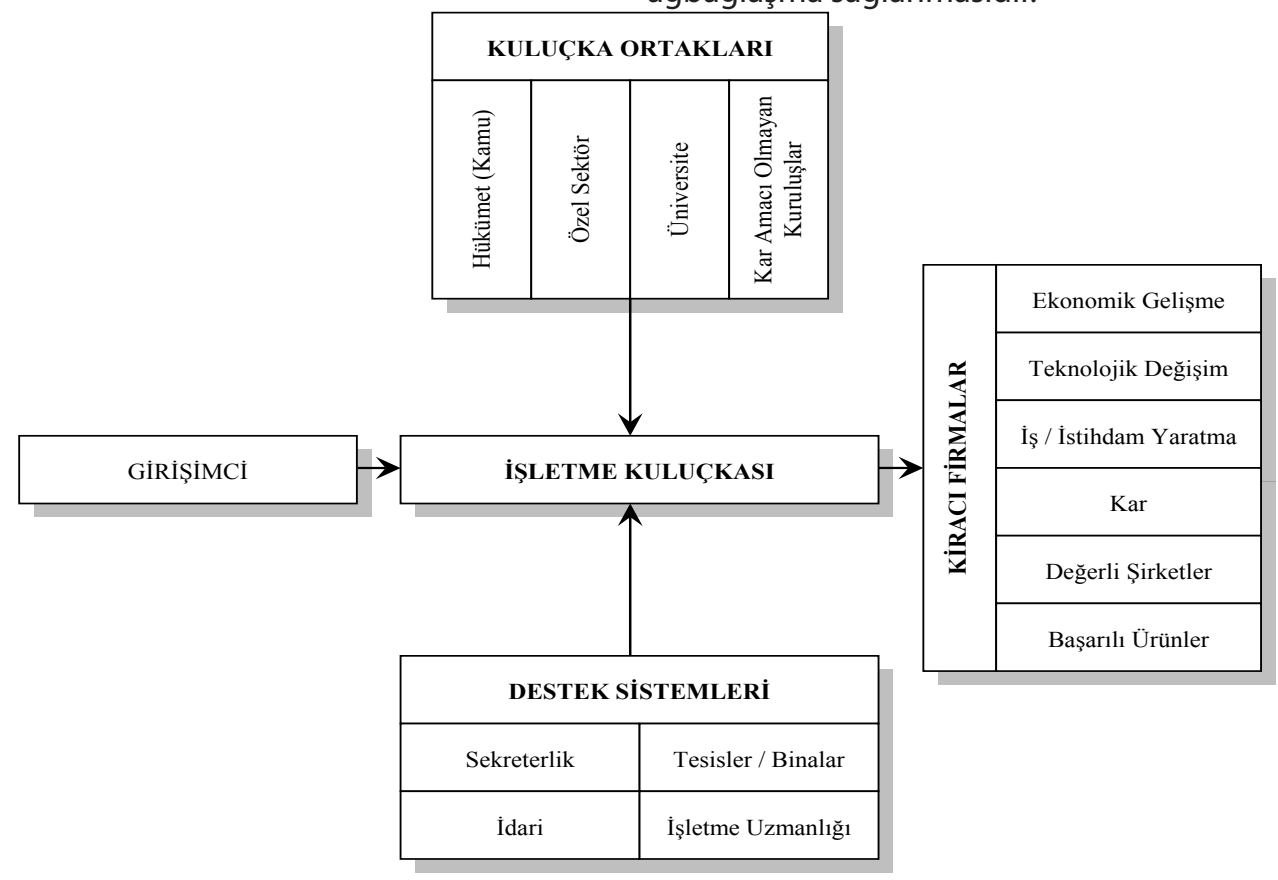

Şekil 1: İşletme Kuluçkalarının Genel Yapısı

(Kaynak: Verma, 2004: 18) 
Kuluçkalar; yeni kurulan girişimleri, iş ve pazarlama planları geliştirilmesi, yönetim ekipleri oluşturulması, sermaye sağlanması ve diğer uzmanlaşmış profesyonel hizmetlere erişim sağlanması gibi çok çeşitli destekleyici hizmetler aracılığıyla desteklemektedir. Bunlara ilaveten, kuluçkalar, paylaşılan/ortak ekipman, idari hizmetler ve esnek ofis alanları da sunmaktadır. Pek çok kuluçka belli ortak hizmetler sunarken, bazıları aynı zamanda kendi müşteri temeline göre farklı hizmetler de sunabilmektedir (Grimaldi ve Grandi, 2005: 111).

İşletme kuluçkaları, fiziksel ofis alanlarına ek olarak, kiracı firmaların hayatta kalma ve büyüme yeteneklerini arttırmayı sağlayacak çok sayıda hizmet sunmaktadır. Bu hizmetler; idari hizmetler, yönetim ve pazarlama desteği, muhasebe, hukuk, yasal ve bürokratik konularda destek, teknoloji danışmanlığı gibi hizmetleri kapsamaktadır (Suk ve Mooweon, 2006: 38). Kuluçka hizmet türleri ile ilgili yapılan çalışmalarda, farklı ayrımlar da bulunmakla birlikte; kuluçka sürecinde öne çıkan 5 temel hizmet grubu tanımlanmaktadır. Bunlar (Carayannis ve von Zedtwitz, 2005:104-105);

- Fiziksel altyapıya erişim: İşletme kuluçkaları; ofis alanı, mobilya, bilgisayar ve internet ağı, güvenlik, spor tesisleri, laboratuar gibi fiziksel altyapı ve mevcut gayrimenkul ile yapılabilecek temel hizmetleri sunmaktadır.

- Ofis desteği hizmetleri: işletme kuluçkaları, altyapıya ilaveten aynı zamanda faks, fotokopi, sekreterlik, posta hizmetleri gibi temel ofis destekleri de sağlamaktadır.

- Finansal kaynaklara erişim: İşletme kuluçkaları; firmaların, girişim sermayedarları, iş melekleri, yerel kuruluşlar, kurumsal yatırımcılar ve şirketlere ulaşmaları için aracı olmaktadır.

- Girişimsel başlangıç desteği / Danışmanlık hizmetleri: Işletme kuluçkaları, yeni ve deneyimsiz olan bir şirketin atması gereken adımlar konusunda yol göstermektedir. Bu konuda; iş planı hazırlanması, muhasebe, hukuki-yasal danışmanlık, vergi konuları, istihdam, planlama gibi konularda yardımcı olmaktadır.

- Ağbağlaşma hizmetleri: Başarılı performans sergileyen işletme kuluçkaları, kiracı firmaların başarısı için anahtar rol oynayan kişi / kurum / kuruluşlarla bağlantılar kuran kuluçkalardır. Girişimciler, özellikle başlangıç yıllarında, bir kuluçkanın yıllar süren girişimleri sonucunda geliştirdiği bağlantılara sahip değildir. İşletme kuluçkaları sayesinde bu girişimciler, kuluçkanın sahip olduğu bağlantılara erişim imkânına kavuşmaktadır.
Dünyadaki ilk uygulaması 1959 yılında ABD'nde başlatılan (Al-Mubaraki vd, 2010: 3; Yu vd, 2009; Albert ve Gaynor, 2001: 4) işletme kuluçkası uygulaması işletme kuluçkası uygulaması zaman içerisinde tüm dünyada hızla yaygınlaşmıştır. Son 10-15 yıldır Türkiye'de bu uygulamaların girişimciliğin teşvik edilmesi amacıyla giderek yaygın bir şekilde kullanıldığı görülmektedir. Türkiye'de işletme kuluçkası tanımlamasına uyan üç yapılanma olduğu görülmektedir. Bunlar; Teknoloji Geliştirme Merkezleri (TEKMER), Duvarsız Teknoloji İnkübatörleri (DTi) ve İş Geliştirme Merkezleri (işGEM)'dir. Türkiye'de ilk defa 1997 yılında gündeme gelen işGEM'ler Türkiye'de bir yerel kalkınma ve girişimcilik geliştirme modeli olarak desteklenmektedir (Özbek, 2008: 55). KOSGEB tarafından işGEM'ler; "Bünyesinde barındırdığı işletmelere, işletme geliştirme koçluğu, destek ağlarına ulaşım, finans kaynaklarına erişim imkânı, uygun koşullarda iş yeri mekânı, ortak ofis ekipmanı, ofis hizmetleri gibi hizmetler sunarak işletmelerin en kırılgan oldukları ilk yıllarını sağlıklı bir şekilde aşmalarını ve büyümelerini sağlamak amacıyla kurulan ve işletilen, İşletme Kuluçkası veya İşletme Fidanlığı olarak da adlandırılan merkezler" olarak tanımlanmaktadır (KOSGEB, 2010: 1). işGEM'ler, işletme kuluçkası mantığına uygun olarak kiracı firmalara esnek ve uygun fiyatlı ofis alanı, ortak kullanım alanları, eğitim ve danışmanlık hizmetleri ve çeşitli ağbağ mekanizmalarına erişim hizmetleri sağlamaktadır.

\section{AĞBAĞ (NETWORK) TEORISI VE AĞBAĞLAŞMA FAALIYETLERININ FIRMA PERFORMANSINA ETKISI}

Ağbağ yaklaşımı özellikle 1990'lı yıllarda hız kazanmış ve bu konuda yapılan çalışmaların sayısı bu tarihten itibaren hızı ı bir şekilde artmaya başlamıştır (Bianchi ve Bellini, 1991: 487-497). Ağbağlaşmanın ve bir ağbağa dahil olmanın önemi son yıllarda çok sayıda araştırmaya konu olmaktadır. Ağbağlaşma kavramı; girişimcilik, inovasyon, endüstriyel bölgeler ve yakınlığa dayalı diğer mekânsal modeller gibi pek çok alanda çalışma konusu olmaktadır (Havnes ve Senneseth, 2001).

Yeung (1994: 476)'a göre ağbağ, "firma içinde, firma dışında ve firmalar arasında ortaya çıkan ve süreklilik arz eden ekonomik ve ekonomik olmayan ilişkiler bütünüdür". Gay ve Dousset (2005: 1460)'e göre ise ağbağ; "firmaları ve firmalar arası etkileşimleri temsil eden, işbirliği (bağlantılar) ile birbirine bağlanmış firmalar (düğümler) topluluğudur".

Firmalar arası ağbağlaşmanın oluşması, yapısı ve ağbağ performansı konularına giderek artan bir ilgi bulunmaktadır. Ağbağlaşmanın, rekabetçi üstünlük- 
ler, yenilikçilik kapasitesi ve firma performansı açısından önemli bir unsur olduğu pek çok çalışmada vurgulanmaktadır (Powell, Koput ve Smith-Doerr, 1996; Dyer ve Singh, 1998; Powell vd., 2005; Owen-Smith vd., 2002; Gay ve Dousset, 2005; Birley, 1985).

İşbirliği ağbağlarında yer alan firmalar, bu ağbağlardan çeşitli şekillerde yararlanmaktadır. Ağbağ içerisindeki firmalar yalnızca faaliyetlerini, risklerini ve maliyetlerini paylaşmamakta aynı zamanda yeni pazarlara ve yeni teknolojilere erişim imkânı elde etmekte, diğer firmaların yeteneklerini kullanmakta ve bilgi paylaşımında bulunmaktadır (Kajikawa vd., 2010). Bu tür kaynaklara ve yetkinliklere erişimin firma performansı etkilemesinden dolayı, ağbağ yapısının firma gelişimi ve firma performansı üzerindeki etkisinin analiz edilmesi önem arz etmektedir.

Ağbağ yapısının ve ağbağ konumunun firma performansını, pazar yapısını ve büyümesi etkilediğini ortaya koyan pek çok çalışma bulunmaktadır (Riccaboni ve Pammolli, 2002). Yeni kurulan girişimsel firmaların gelişimi, büyümesi, performansı ve hayatta kalması, girişimcilik ile ilgili yapılan araştırmaların büyük çoğunluğunu oluşturmaktadır (Gartner, 1985). Girişimsel firmalar içsel kaynakların yetersizliği ve "yeni olmanın engeli" (Stinchcombe, 1965) ve «küçük olmanın engeli" (Freeman, Carroll ve Hannan, 1983: 692) olarak tanımlanan diğer başlangıç zorlukları ile karakterize edilmektedir. Firmalar arası ağbağlaşma aracılığıyla dışsal kaynakların stratejik kullanımı küçük ve yeni olmanın zayıflıklarının üstesinden gelinmesinde etkili bir araç olarak görülmektedir. Bu bağlamda, firmalar arası ağbağlaşma, yeni kurulan girişimsel firmanın büyümesini ve hayatta kalmasını sağlaması açısından, organizasyonel gelişimin önemli bir modeli olarak görülmektedir. Bu konuda Larson ve Starr (1993), ağbağ kalitesi ve bağlantı sayısının, yeni kurulan firma performansını etkilediğini ifade etmektedir. Konu ile ilgili yapılan pek çok ampirik araştırma sonucu da; firmanın firmalar arası ağbağ oluşturmaSı, ağbağ büyüklüğü ve ağbağ büyümesi ile firmanın büyümesi arasında bir ilişki olduğunu ortaya koymaktadır.

Zhao ve Aram (1995) tarafından yapılan çalışmada, ağbağ büyüklüğünün, firma büyümesi ile ilişkili olduğu sonuna ulaşılmıştır. Çalışmada, özellikle firma gelişiminin erken aşamalarında ağbağlaşmanın, firma büyümesini pozitif etkilediği belirtilmiştir. Benzer şekilde, Rothaermel (2001) tarafından yapılan çalışmada da genç firmalar için, ağbağ büyüklüğü ve performans arasında pozitif ilişki bulunmuştur. Hansen (1995) tarafından yapılan çalışmada da, firma kuruluş aşamasında firma kurucusunun kişisel ağbağlarının, izleyen yıldaki istihdam sayısındaki artış (büyüme) ile ilişkili olduğu sonucuna ulaşılmıştır. Brüderl ve Preisendörfer (1998) tarafından yapılan çalışmada, girişimcilerin kişisel ağbağlarının firma hayatta kalma, satış ve istihdam büyümesi üzerindeki etkileri araştırılmış ve çalışma sonucunda ağbağlaşmanın hem hayatta kalma hem de satış ve istihdam büyümesi üzerinde etkili olduğu sonucuna ulaşılmıştır. Ostgaard ve Birley (1996) tarafından 159 firma üzerine yapılan araştırmada, ağbağlaşma ile firma büyümesi arasında bağlantı olduğu sonucuna ulaşılmıştır. Dean, Holmes ve Smith (1997) tarafından yürütülen çalışmada ise ağbağlaşmanın, karlılık, istikrarlı büyüme, ürün ve hizmet kalitesi, satışlar üzerinde pozitif etkileri olduğu belirlenmiştir. Konuyla ilgili ampirik çalışma sayısı oldukça fazladır ve bu örnekleri çoğaltmak mümkündür. Sonuç olarak; daha fazla ağbağa sahip olan firmalar; daha az ağbağa sahip olan firmalardan daha iyi performans sergilemektedir (Havnes ve Senneseth, 2001: 293-295).

\section{IŞLETME KULUÇKALARINDA AĞBAĞLAŞMA}

Girişimsel ağbağların ve işbirlikçi ilişkilerin yeni kurulan girişimler açısından özellikle başlangıç yıllarında büyük önemi bulunmaktadır. Bu nedenle, kiracı firmaların hayatta kalmalarını sağlamak amacıyla işletme kuluçkaları da kritik bir hizmet ve destek uygulaması olarak kiracı firmalar arasında ağbağlaşma faaliyetlerini desteklemelidir.

Genel olarak işletme kuluçkalarında ağbağlaşma faaliyetleri;

1- Kuluçka içerisinde yer alan kiracı firmaların kendi aralarında, kuluçka yönetimi ve kuluçka ekibi arasında ortaya çıkan ağbağlaşma faaliyetlerini ifade eden "içsel" ağbağlaşma,

2- Kuluçka içerisinde yer alan kiracı firmalar ile kuluçka dışı firmalar ve diğer aktörler arasında ortaya çıkan ağbağlaşma faaliyetlerini ifade eden "dışsal" ağbağlaşma olarak ele alınmaktadır.

İçsel ağbağlaşma açısından bakıldığında; işletme kuluçkalarının önemli bir rolü de, kuluçkada yer alan kiracı firmalar arasında bir aracılık görevi görmesidir (Peters, Rice ve Sundararajan, 2004). İşletme kuluçkası uygulamaları, firmalar arasında uygun ağbağların yaratılmasını ve sürdürülmesini kolaylaştıran bir platform sağlayabilmektedir. Kuluçkalar, firmaları diğer aktörler ile eşleştirerek ağbağ kurulması konusunda aracılık sağlamakta ve yeni kurulan girişimlerin, henüz ilk aşamada bağlantılarının az olmasından ve güçlü bir ağbağ sahibi olmamalarından kaynaklanan zayıfıkları telafi etmektedir (Smilor, 1987). Kuruluşun 
ilk yıllarında ve gelişme aşamasında, işbirlikçi ilişkiler geliştirilmesi, zorlu yılların başarılı bir şekilde geçilmesi açısından önem arz etmektedir. Bu tür ağbağlara erişim, küçük girişimsel firmaların yeni ve küçük olmalarından kaynaklanan birtakım zorlukların üstesinden gelmelerine yardımcı olabilmekte ve girişimin erken aşamalarında kritik olan işbirlikçi ilişkilerin gelişmesini desteklemektedir (McAdam ve Marlow, 2007: 363). Kiracı firmalar arasındaki etkileşim aynı zamanda sosyal sermaye oluşması ve yığışma ekonomilerinin (agglomeration economies) ortaya çıkmaSı açısından önem arz etmektedir (Aernoudt, 2004, Bhabra-Remedios ve Cornelius, 2003; Brooks, 1986; Colombo ve Delmastro, 2002).

Kuluçkalar, ortak girişimsel amaçları olan, benzer büyüme aşamasında olan ve ilişkili sektörlerde faaliyet gösteren firmaların yakın olarak bir araya gelmesiyle pozitif bir kümelenme etkisi yaratmaktadır (McAdam ve Marlow, 2007: 364). Kuluçkanın yarattığı bu kümelenme etkisi, kümelenmelerde ortaya çıkan pozitif dışsalıkların (bilgi ve işgücü havuzu, sinerji, ağbağ gibi) ortaya çıkmasını sağlamaktadır (McAdam ve Marlow, 2008: 222). De Clerq ve Arenius'a (2006: 342-343) göre; paylaşılan bilgi ve uzmanlıkla firmaların bir araya gelmesi, girişimsel süreç ile ilgili belirsizlikleri azaltmaktadır. Kümelenme, birbirine yakın olarak konumlanan belirli tür firmalar arasında bilgi, deneyim ve uzmanlıkların paylaşıldığı pozitif bir sinerji yaratmaktadır. Bu bakımdan kuluçkalar; kuluçka içerisinde yer alan firmaların intiyaç duyduğu finans, muhasebe, yönetim, teknoloji, satış, pazarlama, reklam, eğitim, insan kaynakları gibi firmaların ihtiyaç duyabilecekleri tüm bilgileri bir araya getiren ve bir bilgi kümelenmesi oluşturan uygulamalardır.

Kuluçkalar, firmaları tek bir çatı altında toplayarak ve onlara kafeterya, toplantı odası gibi ortak alanlar sağlayarak, birbirleriyle etkileşim kurmalarını ve aralarında bir sinerji doğmasını sağlayacak bir ortam ve fırsat sağlayabilmektedir. Bu ortam, kiracıların birbirleriyle kendiliğinden ve yakın iletişim kurmasını, kaynak ve deneyim paylaşmasını sağlamaktadır (Abduh vd, 2007: 76-77). Abduh vd. (2007)'ne göre; doğru bir ortam yaratılması durumunda, firmalar birbirleriyle iletişim kuracak ve yakın iletişim kurmak sayesinde birbirleriyle kaynakları ve deneyimleri paylaşarak birbirlerinden karşılıklı olarak öğreneceklerdir. Pennsylvania işletme kuluçkasında yer alan kiracı firmalar ile yapılan çalışmada da, kiracı firmaların \%75'inin diğer kiracılarla ilişki kurdukları sonucuna ulaşılmıştır (Aernoudt, 2004: 130).

Dolayısıyla, kuluçka içerisinde içsel bir ağ oluşturulmasında ilk adım; paylaşılan / ortak mekânlar oluşturulmasıdır. Çünkü bilgi paylaşımının ve karşılıklı öğ- renmenin ortaya çıkabilmesi için özellikle insanların birbirlerini iyi tanımaları ve birbirlerine güvenmeleri gerekmektedir. Bu nedenle kuluçka yöneticileri; insanların tanışabileceği, birbirleriyle etkileşim kurabileceği ve ağ ilişkileri oluşturabileceği ortamlar yaratılmasında aktif bir rol oynamalıdır.

Bununla birlikte; kuluçka içerisinde ortaya çıkan ağbağlaşma, yalnızca kiracı firmaların kendi aralarında oluşturdukları ağbağlaşma ile sınırlı değildir. Kiracı firmalar ile kuluçka yönetimi ve kuluçka uzman personeli arasında ortaya çıkan sürekli ve yakın işbirliği ve ağbağlaşma da kiracı firmalar açısından son derecede önemli kaynaklar olmaktadır. Kuluçka içerisinde, kuluçka yönetimi ile kiracı firmalar arasında ortaya çıkan ilişkiler, kuluçka ağbağlarında güvene ve normlara dayalı sosyal sermaye oluşmasını ve kuluçka ağbağları aracılığıyla ortaya çıkan yararlar elde edilmesini sağlamaktadır (Scillitoe ve Chakrabarti, 2010: 158).

Literatürde, işletme kuluçkalarının ağbağlaşmayı kolaylaştırıcı rolünü vurgulayan ve ağbağlaşmanın kiracı firma performansına etkisini ele alan çok sayıda çalışma bulunmaktadır (Lumpkin ve Ireland, 1988; Sherman, 1999; Hansen vd, 2000; Adegbite, 2001; Bollingtoft ve Ulhoi, 2005; McAdam ve Marlow, 2007; McAdam vd, 2006; Zhang ve Jiang, 2009; Scillitoe ve Chakrabarti, 2010). Yapılan çalışmalar, işletme kuluçkaları ağbağlarının girişimsel süreç üzerinde oldukça olumlu etkileri olduğunu ortaya koymaktadır. Ancak, kuluçka literatüründe, ağbağlaşma faaliyetleri genellikle işletme kuluçkaları hizmetlerinden birisi olarak ele alınmakta ve firma büyüme ve hayatta kalma üzerindeki etkisi diğer kuluçka hizmetleri ile birlikte ele alınmaktadır. Yalnızca kiracı firmalar arasındaki ağbağlaşmanın yeni firma performansına etkisine odaklanan ampirik çalışma sayısı oldukça azdır.

Tötterman ve Sten (2005) tarafından yapılan çaIışmada, girişimcilerin yeni ağbağlar oluşturması konusunda kuluçkaların oynadığı roller araştııılmıştır. Çalışma kapsamında, Finlandiya'da 3 farklı bölgede yer alan 3 iş kuluçkası ele alınmıştır. Çalışmada, kuluçka personeline ek olarak; hem hala kuluçkada yer alan 28 firma ile hem de kuluçkadan mezun olmuş 40 firma ile görüşülmüştür. Çalışma sonucunda, iş veya destekleyici ağbağların kurulması konusunda kuluçkalardan önemli destekler alan girişimcilerin, bu destekleri almayan girişimlere göre daha memnun olduğu sonucuna ulaşılmıştır.

Rothaermel ve Thursby (2005) tarafından yapılan çalışmada; işletme kuluçkasında yer alan 79 kuluçka firma incelenmiş ve üniversite ile olan bağlantının kuluçka firma mezuniyeti veya başarısızlığı üzerinde etkisi olup olmadığı araştırılmıştır. Çalışmada, üni- 
versite ile olan güçlü bağlantıların, firma başarısızlık olasılığını azalttığı, ancak aynı zamanda kuluçkadan mezuniyeti de geciktirdiği sonucuna ulaşılmıştır.

Suk ve Mooweon (2006) tarafından yapılan çalışmada, Kore'deki 259 kuluçka incelenmiş, yapılan çalışma sonucunda, destekleyici hizmetlerin çeşitliliği ve kalitesi, tam zamanlı personelin bulunması ve ağbağlaşmanın, söz konusu kuluçkalarda fark edilir derecede daha iyi bir performans yarattığı sonucuna ulaşıımıştır.

Zhang ve Jiang (2009) tarafından yapılan çalışmada, işletme kuluçkalarındaki ağbağlaşma eylemleri ve firma performansına etkisi incelenmiştir. Çalışma kapsamında, işletme kuluçkasında yer alan mevcut firmalarla ve kuluçkadan mezun olmuş firmalarla görüşülmüştür. Firma performans değişkenleri olarak; (1) finansal operasyonel yetenekler, (2) piyasa rekabetçiliği, (3) inovasyon öğrenme yeteneği, (4) organizasyon ve koordinasyon yeteneği, (5) şartlara uyum sağlayabilme yeteneği, (6) işbirlikçi yetenekler kullanılmıştır. 121 firma ile yapılan çalışma sonucunda; ağbağlaşma mekanizmaları ile performans arasında yakın bir korelasyon olduğu ve söz konusu mekanizmaların, daha iyi performans konusunda açıklayıcı olduğu sonucuna ulaşılmıştır.

Peters, Rice ve Sundararajan (2004) tarafından 42 işletme kuluçkası üzerine yapılan çalışmada, işletme kuluçkalarında sunulan hizmetler ile kuluçka performansı arasında bir ilişki olup olmadığı araştırılmıştır. Çalışma sonucunda, altyapı hizmetleri sunan kuluçkalar arası mezun sayısı açısından önemli bir farklııık görülmezken, ağbağlaşma hizmeti sunan ve sunmayan kuluçkalar arasında mezun sayısı açısından \%10 önem seviyesinde önemli bir farklıılık bulunmuştur.

\section{METODOLOJi}

Bu çalışmanın amacı, işletme kuluçkalarında yer alan firmaların birbirleriyle olan işbirliği ve ağbağlaşmanın yeni kurulan girişimlerin hayatta kalma olasılığı üzerindeki etkisinin araştırılmasıdır. Literatürde işletme kuluçkalarının firmaların birbirleriyle işbirliği yapmasını ve ağbağlaşmayı teşvik ettiği ve bu sayede ağbağlaşma içerisinde olan firmaların ağbağlaşma içerisinde olmayan firmalara göre hayatta kalma olasılıklarının arttığı vurgulanmaktadır. Bu çalışma, bu teoriyi test etmeyi amaçlamaktadır.

Çalışma, TÜBITAK 109K139 nolu "Iş Kuluçkalarında Yeni Kurulan Girişimlerin Hayatta Kalma ve Büyüme Performansını Etkileyen Faktörler: KOSGEB İş Geliştirme Merkezleri (IŞGEM) Üzerine Bir Araştırma" konulu proje kapsamında yürütülen çalışmanın verilerinden yararlanmaktadır. Bu kapsamda; Türkiye'de
10 ilde yer alan toplam 12 işGEM kapsanmaktadır. Bunlar; Zonguldak, Ereğli, Eskişehir, Samsun, Yozgat, Nevşehir, Mersin, Tarsus, Adana, Elazığ, Diyarbakır ve Van işGEM'dir. Çalışma, işGEM'lerde yer alan ve işGEM'lerden daha önce mezun olan 553 firmanın 414'ünü kapsamaktadır.

Tablo 1: Araştırmaya Katılan Firma Sayıları

\begin{tabular}{|l|c|l|}
\hline Araştırmaya Katılan Firma Özellikleri & \multicolumn{2}{|c|}{ Sayı } \\
\hline $\begin{array}{l}\text { Iş̧GM Dışına Çıkmış Kapanan Firma } \\
\text { Sayısı }\end{array}$ & 83 & (a) \\
\hline $\begin{array}{l}\text { IşGEM Dışına Çıkmış Hayatta Olan Firma } \\
\text { Sayısı }\end{array}$ & 93 & (b) \\
\hline I̧̧̧GEM Dışına Çıkmış Firmalar & 176 & (c) $=(a+b)$ \\
\hline İ̧̧GEM İçinde Olan Firma Sayısı & 238 & (d) \\
\hline I̧şGEM Sürecinden Geçen Firma Sayısı & 414 & (e) $=(c+d)$ \\
\hline Hayatta Olan Firma Sayısı & 331 & (f) $=(b+d)$ \\
\hline
\end{tabular}

Yöntem itibariyle çalışma, 414 firma ile yapılan yüz yüze görüşme ve anket uygulamasına dayanmaktadır. Anketin hazırlanmasında, literatürde işletme kuluçkaları, işbirliği/ağbağlaşma, hayatta kalma teorisi konularında yapılan çalışmalardan yararlanılmıştır. Bu kapsamda; Demirgil (2008), Verma (2004), Shahidi (1998), Köseoğlu (2007) ve Sungur (2007) tarafından yapılan çalışmalarda uygulanan anketlerden yararlanılmıştır.

Proje kapsamında uygulanan anketten elde edilen veriler Stata 12 programı ile değerlendirilmiştir. Yöntem olarak "hayatta kalma analizi" (survival analysis) kullanılmıştır. Analiz kapsamında; Kaplan-Meier hayatta kalma analizi (Kleinbaum ve Klein, 2005; Göz Çekçeki, 2007; Demirgil, 2008; Karaöz ve Albeni, 2011; Karaöz, Albeni ve Demirgil, 2011; Demirgil vd, 2011; Anavatan, 2011) kullanılmıştır.

Hayatta kalma analizine yönelik olarak; STATA programı ile yapılan analiz için toplam 414 gözlem kullanılmıştır. Ancak bu gözlemlerden 10 tanesinin, kuluçkaya girdiği veya kuluçkadan çıktıları tarih belli olmadığı için analize dâhil edilememiştir. Sonuç olarak, 403 firma üzerinden hayatta kalma analizi yapılmıştır.

Hayatta kalma analizi için kullanılan "olay" ise, firmanın işGEM içerisindeyken kapanıp kapanmamasıdır. Buna yönelik olarak kullanılan "FAILURE" değişkeninde, firma işGEM içerisindeyken kapanmışsa 1 değeri, kapanmamışsa 0 değeri verilmiştir. Analizde, işGEM hizmetlerinin firmaların hayatta kalma olasılıkları üzerindeki etkilerini ölçmek amacıyla sadece işGEM içerisindeyken kapanan firmalar dikkate alınmış, işGEM'lerden başarılı bir şekilde mezun olduktan sonra kapanan firmalar dikkate alınmamıştır. 


\section{BULGULAR}

\subsection{Firma Hayatta Kalma Oranları}

Araştırmada ilk olarak, 403 firma üzerinden hayatta kalma analizi yapılmıştır. Buna göre; firmalar için maksimum hayatta kalma süresi 158 ay olarak belirlenmiştir (Şekil 2). Firmaların büyük çoğunluğu ilk 50 ay içerisinde kapanmakta, 50. aydan sonra hayatta kalabilen firmaların kapanma olasılıkları ise azalmaktadır. Buna göre; firmaların yaklaşık \%15'i ilk 2 sene (24 ay) içerisinde kapanmaktadır. Ancak 24 aydan sonra kapanma oranlarında bir miktar yavaşlama olduğu ve hayatta kalma olasılıklarının \%85 civarında sabitlendiği görülmektedir. 24-30. aylar arasında görece sabit olan hayatta kalma olasılıklarında yaklaşık 30. aydan itibaren bir miktar düşüş yaşanmakta, 40. aydan itibaren ise hayatta kalma olasılığı sabitlenerek \%75 civarında olmaktadır.

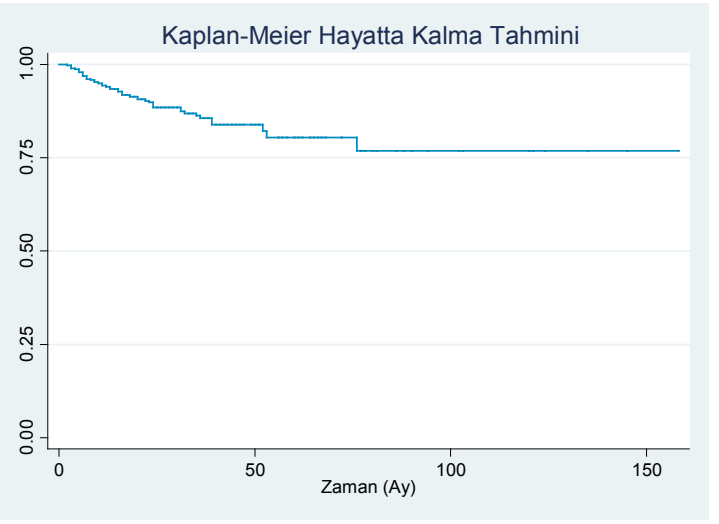

Şekil 2: Kaplan-Meier Hayatta Kalma Olasılıkları

Aşağıdaki grafikte (Şekil 3) ise; hayatta kalma oranları sunulmaktadır. Buna göre; başlangıçta tüm firmalar hayatta iken, 24. ayda analizde yer alan firmalar içerisinde hayatta kalan firma oranııın $\% 50$ 'lere düştügü, 36 . ayda ise \%30'lar düzeyine düştüğü görülmektedir. 50. aydan itibaren gözlemlenen veriler içerisinde hayatta kalan firma oranı \%20'nin altına düşmekte ve son gözlem olarak 158. ayda hayatta kalan firma oranı sıfır olmaktadır.

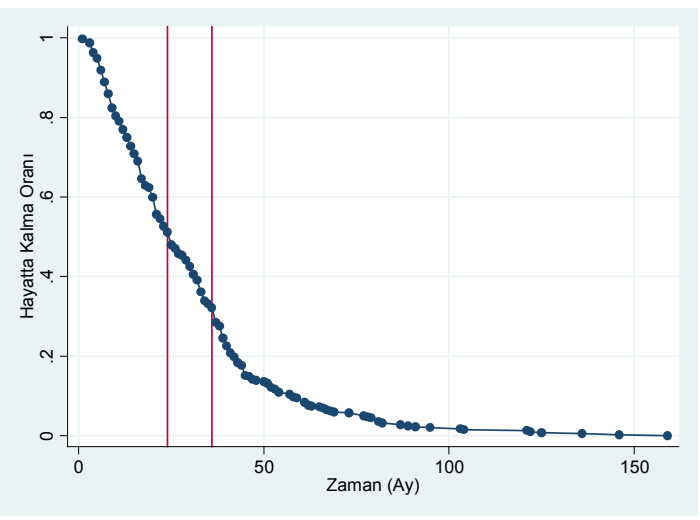

Şekil 3: Kaplan-Meier Hayatta Kalma Oranları

\subsection{Firmalar Arası İşbirliği}

Araştırmaya katılan 414 firmanın 256'sı, en az 1 firma ile işbirliği içerisinde iken, 158 firmanın hiçbir firma ile herhangi bir işbirliği/ağbağlaşma faaliyeti bulunmamaktadır (Tablo 2). Diğer firmalar ile işbirliği içerisinde bulunmayan 156 firmanın 70'nin hayatta kalamadığı (kapandığı) tespit edilmiştir. Bununla birlikte; hayatta olan firmalardan 88'inin de diğer firmalarla herhangi bir işbirliği olmadığı sonucuna ulaşımaktadır.

Tablo 2: Firmalar Arası İşbirliği

\begin{tabular}{|r|c|c|l|}
\hline & Hayatta & Kapanan & Toplam \\
\hline İşbirliği Yapan & 88 & 70 & 158 \\
\hline İşbirliği Yapmayan & 243 & 13 & 256 \\
\hline Toplam & 331 & 83 & 414 \\
\hline
\end{tabular}

İşbirliği düzeyine ayrıntılı olarak bakıldığında ise (Tablo 3); 414 firmanın 158'nin hiçbir firma ile işbirliği faaliyetinde bulunmadığı görülmektedir. Bununla birlikte, 24 firmanın çok düşük düzeyde, 36 firmanın düşük düzeyde, 47 firmanın orta düzeyde işbirliği faaliyetlerinde bulunduğu ortaya çıkmaktadır. Araştırmaya katılan 414 firmanın toplam 149'nun ise yüksek (99 firma) ve çok yüksek (50 firma) düzeyde diğer firmalarla işbirliği bulunmaktadır.

Tablo 3: Firmalar Arası İşbirliği Düzeyi

\begin{tabular}{|r|l|l|}
\hline İşbirliği Düzeyi & Sayı & Yüzde \\
\hline Yok & 158 & 38,16 \\
\hline Çok Düşük & 24 & 5,80 \\
\hline Düşük & 36 & 8,70 \\
\hline Orta & 47 & 11,35 \\
\hline Yüksek & 99 & 23,91 \\
\hline Çok Yüksek & 50 & 12,08 \\
\hline Toplam & 414 & 100,00 \\
\hline & &
\end{tabular}

Hayatta kalan ve hayatta kalmayan firmalar açısında işbirliği/ağbağlaşma düzeyleri ise çarpıcı sonuçlar ortaya koymaktadır (Tablo 4). Araştırma kapsamında incelenen 414 firma içerisinde hayatta olan 331 firmanın diğer firmalarla işbirliği/ağbağlaşma düzeyi 2,577 iken, hayatta kalamayan (kapanan) 83 firmanın diğer firmalarla işbirliği/ağbağlaşma düzeyi 0,361 olmaktadir.

Tablo 4: Firma Durumuna Göre İşbirliği Düzeyi Ortalamaları

\begin{tabular}{|r|l|l|l|l|l|}
\hline $\begin{array}{r}\text { Firma } \\
\text { Durumu }\end{array}$ & Gözlem & Ortalama & $\begin{array}{l}\text { Std. } \\
\text { Sapma }\end{array}$ & $\begin{array}{l}\text { Mini- } \\
\text { mum }\end{array}$ & $\begin{array}{l}\text { Maksi- } \\
\text { mum }\end{array}$ \\
\hline $\begin{array}{r}\text { Hayatta } \\
\text { Olan }\end{array}$ & 331 & 2,577 & 1,854 & 0 & 5 \\
\hline Kapanan & 83 & 0,361 & 0,995 & 0 & 4 \\
\hline
\end{tabular}




\subsection{Firmalar Arası İşbirliğinin Hayatta Kalma Üzerine Etkisi}

İsbirliğinin hayatta kalma üzerindeki etkisi ise Kaplan-Meier hayatta kalma grafikleri ile ortaya koyulmaktadır. Bu kısımda, kiracı firmaların kendi aralarında işbirliği içerisinde olmaları ve ağbağlaşmalarının firmaların hayatta kalmaları üzerinde bir etkisi olup olmadığı araştırıımıştır. Bu amaçla; firmalara, IŞGEM içerisindeki diğer firmalarla herhangi bir konuda ilişki ve işbirliği kurup kurmadıkları sorulmuş ve buna göre ağbağlaşma durumuna göre iki kategori oluşturulmuştur. Bu kapsamda, hiçbir firma ile ilişki kurmayan firmalar ile ilişki kuran firmaların hayatta kalma olasıııkları karşılaştırılmıştır. Analize ilişkin Kaplan-Meier hayatta kalma eğrileri aşağıda (Şekil 4) sunulmaktadır.

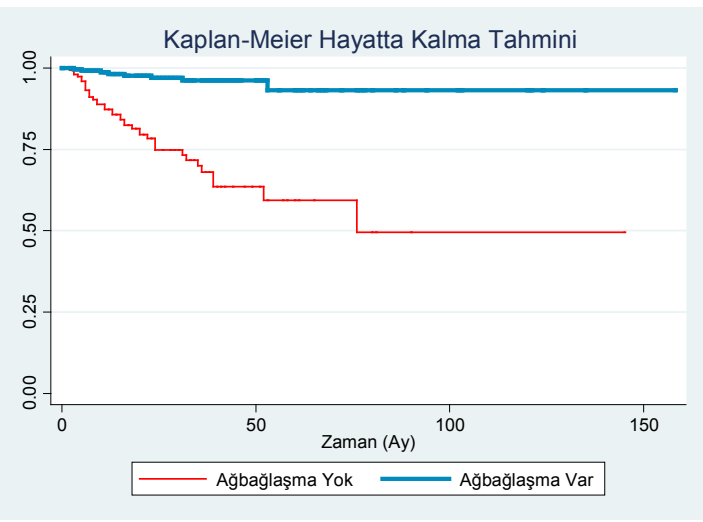

Şekil 4: Firmalar Arası Ağbağlaşmanın Hayatta Kalma Üzerine Etkisi

Buna göre; IŞGEM içerisinde diğer firmalar ile ilişki içerisinde olmanın ve işbirliği kurmanın hayatta kalma üzerinde etkisi olduğunu söylemek mümkündür. işGEM içerisinde hiçbir firma ile ilişki kurmayan firmaların hayatta kalma olasılıkları \%50 iken, en az bir firma ile işbirliği kuran ve ağbağlaşmaya dahil olan firmaların hayatta kalma olasılıkları $\% 90$ 'lar seviyesindedir.

Diğer firmalar ile işbirliği içerisinde olmayan firmalar, yüksek düzeyde bir başarısızlık oranıyla karşı karşıya kalmaktadır (Şekil 5). Kaplan-Meier hata tahminlerine ilişkin elde edilen analiz sonucuna göre; diğer firmalarla hiçbir işbirliği içerisinde olmayan firmaların başarısızlık oranları \%50'lere kadar çıkarken, işbirliği faaliyetlerinde bulunan firmalarda başarısızlık oranları \%7 gibi çok düşük bir düzeyde kalmaktadır.

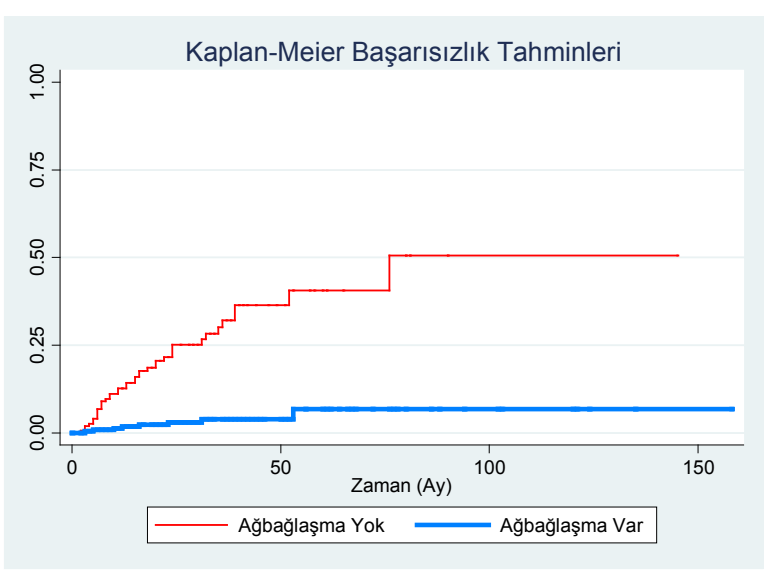

Şekil 5: Firmalar Arası Ağbağlaşmanın Başarısızlık Oranlarına Etkisi

Kaplan-Meier hayatta kalma eğrilerinin anlamlılığını test etmek amacıyla uygulanan Log-Rank (LR) testine ait sonuçlar aşağıdaki tabloda (Tablo 5) sunulmaktadır. Buna göre; diğer kiracı firmalar ile ilişki kuran firmalar ile ilişki kurmayan firmaların hayatta kalma olasılıkları arasında anlamlı bir fark bulunmaktadır. Tablodaki Pr>Chi2 değeri 0,05'ten küçük olduğu için, IşGEM içi kiracı firmalar arasındaki ağbağlaşmanın hayatta kalma olasılığı üzerinde bir fark yarattığını söylemek mümkündür.

Tablo 5: Log-Rank Testi Sonuçları

\begin{tabular}{|r|l|l|l|}
\hline Ağbağlaşma & $\begin{array}{l}\text { Gözlenen } \\
\text { Olaylar }\end{array}$ & $\begin{array}{l}\text { Beklenen } \\
\text { Olaylar }\end{array}$ & \\
\hline Yok & 39 & 16.23 & Chi2(1) $=49.19$ \\
\hline Var & 8 & 30.77 & $\operatorname{Pr}>$ Chi2 $=0.0000$ \\
\hline Toplam & 47 & 47.00 & \\
\hline
\end{tabular}

Hayatta kalma fonksiyonuna ilişkin olarak orantılılık testine (PH test) ait gözlenen ve tahmin edilen değerler grafiği aşağıda (Şekil 6) sunulmaktadır. Söz konusu grafik, Kaplan-Meier hayatta kalma modeli ile gözlenen değerler ile hayatta kalma için oluşturulan Cox Orantılı Hazard Regresyon modeli sonucunda tahmin edilen değerleri karşılaştırmaktadır. Gözlenen değerlerin tahmin edilen değerlere yakın olması, hayatta kalma grafiklerinin anlamlıığını doğrulamaktadır. Buna göre; LR testi tarafından da doğrulandığı üzere; diğer firmalarla işbirliği kuran ve kurmayan firmaların hayatta kalma olasılıkları arasında anlamlı bir farklılık bulunmaktadır. 


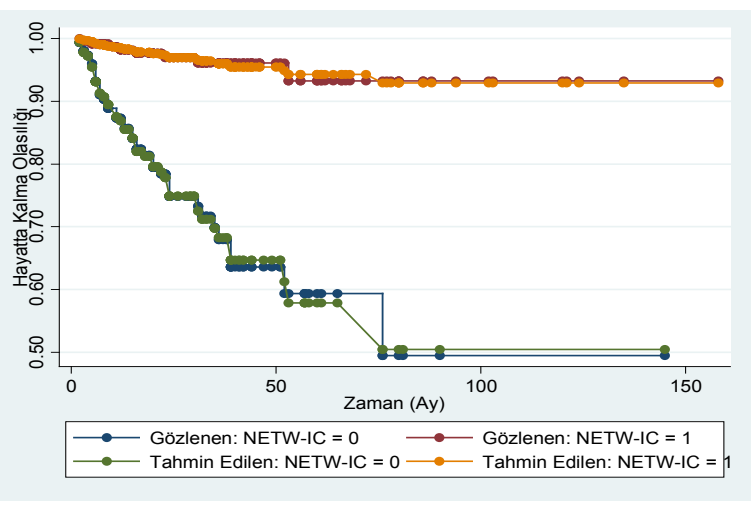

Şekil 6: PH Testi Sonuçları

Ağbağlaşmanın hayatta kalma üzerindeki etkisine yönelik bir diğer önemli bulgu da; ağbağlaşma düzeyinin arttıkça hayatta kalma olasılığının da artmasıdır. Aşağıdaki şekilde (Şekil 7), firmaların diğer firmalarla işbirliği düzeylerine elde edilen hayatta kalma eğrileri yer almaktadır. Buna göre; orta düzeyde işbirliği/ağbağlaşma faaliyetlerinde bulunan firmalarda hayatta kalma olasılıkları (\%94), hiçbir firma ile işbirliği/ağbağlaşma faaliyeti içerisinde olmayan firmaların hayatta kalma olasılıklarından (\%50) yüksek olmaktadır. Çok yüksek düzeyde işbirliği/ağbağlaşma faaliyetlerinde bulunan firmaların hayatta kalma olasılıkları ise diğer tüm firmaların hayatta kalma olasılıklarından daha yüksek olmaktadır.

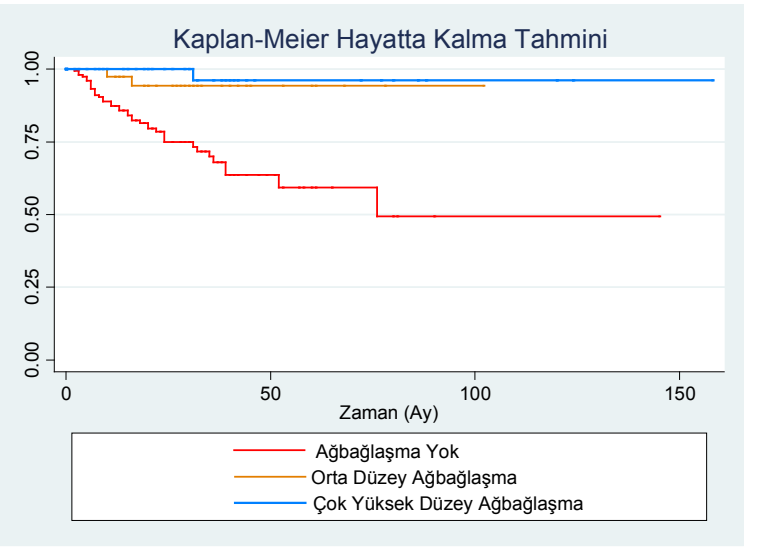

Şekil 7: Firmalar Arası Ağbağlaşma Düzeyinin Hayatta Kalma Üzerine Etkisi

Bu durumda, ağbağlaşma faaliyetlerinde bulunmayan firmaların hayatta kalma olasılıklarının, herhangi bir düzeyde ağbağlaşma faaliyeti içerisinde bulunan firmalarla karşılaştırıldığında en düşük düzeyde olduğu görülmektedir. Bununla birlikte, ağbağlaşma faaliyetlerinde bulunmakla birlikte bu faaliyetleri arttırmanın da hayatta kalma olasılığı üzerinde giderek artan bir etkisi bulunmaktadır.

\section{SONUÇ VE ÖNERILER}

Firmalar arasındaki yakınlık ve belli bir konumda kümelenmeler, işbirliği ve ağbağlaşmayı kolaylaştırmakta ve böylelikle firmalar arasında sinerji yaratmaktadır. Bu nedenle; firmaların yakınlaşmasını sağlayan bir uygulamaya olarak işletme kuluçkaları, firmalar arası ağbağlaşmanın ortaya çıkmasını sağlayabilmekte, bu da firmaların performansını arttırarak onların hayatta kalma ve kuluçkadan başarılı bir şekilde mezun olma olasılığını arttırabilmektedir.

Bu çalışma, işletme kuluçkalarının firmalar arasındaki işbirliğinin hayatta kalma üzerinde anlamlı bir etki yaratıp yaratmadığını test etmeyi amaçlamıştır. Literatürde işletme kuluçkalarının firmaların birbirleriyle işbirliği yapmasını ve ağbağlaşmayı teşvik ettiği ve bu sayede ağbağlaşma içerisinde olan firmaların ağbağlaşma içerisinde olmayan firmalara göre hayatta kalma olasıııklarının arttığı vurgulanmaktadır. Bu teorinin test edilmesi amacıyla Türkiye'de 12 İş Geliştirme Merkezi'nde 414 firmadan elde edilen veriler doğrultusunda hayatta kalma analizi uygulanmıştır. Ancak burada vurgulanması gereken bir husus bulunmaktadır. Bu çalışma; hiçbir surette "kuluçka" sürecinden geçmemiş kuluçka-dışı firmaları kapsamamaktadır. Bu çalışma, işletme kuluçkalarında hayatta kalan firmalar ile kuluçka sürecinden geçmeyen kuluçkadışı firmaların hayatta kalma oranlarının karşılaştırılıp, bunun sonucunda da "işletme kuluçkalarının hayatta kalma oranını arttırdığı"yönünde bir bulgu ortaya koyulmasını amaçlamamaktadır. Bu çalışmanın amacı, işletme kuluçkası içerisinde olmasına rağmen diğer firmalarla işbirliği kuran veya kurmayan firmaların hayatta kalma olasılıkları arasında ciddi bir farklılık olup olmadığını ortaya koymayı amaçlamaktadır.

Elde edilen sonuçlar, işletme kuluçkalarında diğer firmalar ile işbirliği içerisinde olan firmaların hayatta kalma olasılıklarının büyük ölçüde arttığını ortaya koymaktadır. Hiçbir firma ile işbirliği içerisinde olmayan firmaların hem hayatta kalma olasılıkları büyük ölçüde düşmekte hem de başarısızlık oranları ciddi bir şekilde artmaktadır.

Buna göre; işletme kuluçkaları içerisinde firmalar arası ağbağlaşmanın desteklenmesi, küçük işletmelerin büyüme ve hayatta kalma olasılıklarını arttıracaktır. IŞGEM açısından ele alınacak olursa; ağbağlaşmayı destekleyici faaliyetler, bu kuluçkalarda desteklenen firmaların hayatta kalma ve mezun olduktan sonra da faaliyetlerine devam etmelerini sağlayacak ve böylece işGEM'lerde sunulan hizmetlerin boşa gitmemesini ve bir politika aracı olarak işGEM'lerin etkinliğinin arttııımasını sağlayacaktır. 
$\mathrm{Bu}$ hususta; firmalar arası işbirliğini tetikleme konusunda bazı hususlara dikkat edilmesi gerekmektedir. Yapılan son çalıșmalarda, kuluçka içerisinde kaynak paylaşımı ve iletişim süreçleri için kiracı uyumluluğunun gerekliliği vurgulanmaktadır (Bollingtoft ve Ulhoi, 2005: 278; Chan ve Lau, 2005: 1217; Tötterman ve Sten, 2005: 505). İşbirliğini tetiklemek için, firmalar arasında bilgi temelleri, yetkinlikler ve pazar odağı açısından belli bir derecede uyumluluğa ihtiyaç vardır. Daha homojen bir kiracı yapısından dolayı uzmanlaşmış işletme kuluçkaları işbirliği için daha güçlü bir platform oluşturmaktadır (Schwartz ve Hornych, 2010: 486). Hansen vd (2000: 80), kiracI firmaların ilişkili sektörlerde olması durumunda birbirleriyle ilişki kurmanın avantajlarının daha yüksek olacağını belirtmektedir. Bu nedenle, bazı işletme kuluçkaları, bilgi ve enformasyon teknolojileri, yazılım, biyoteknoloji, biyokimya, medya gibi belli endüstrilere odaklanmakta ve sadece bu sektörlerde faaliyet gösteren firmalara hizmet vermektedir.

Son olarak, IŞGEM içi firmalar arası ağbağlaşmaya ilaveten, IŞGEM içi firmaların dışsal aktörler ile ağbağlaşmalarının da desteklenmesi önem arz etmektedir. Çünkü işletme kuluçkaları, sadece firmalara kira desteği, başlangıç sermayesi desteği, ofis desteği sağlayan yapılanmalar değil, dünyadaki başarılı uygulamalara da bakıldığında hem kuluçka içi hem de kuluçka dışı ağbağlaşma için başarılı birer köprü oluşturan yapılanmalardır. 


\section{SON NOTLAR}

Bu çalışma, TÜBİTAK 109K139 nolu "İş Kuluçkalarında Yeni Kurulan Girişimlerin Hayatta Kalma ve Büyüme Performansını Etkileyen Faktörler: KOSGEB İş
Geliştirme Merkezleri (İŞGEM) Üzerine Bir Araştırma” başlik proje ve ve SDÜ-BAP 2684-D-11 nolu proje ile desteklenmiştir.

\section{KAYNAKLAR}

Abduh, M., D’Souza, C., Quazi, A. ve Burley, H.T. (2007) "Investigating and Classifying Clients' Satisfaction with Business Incubator Services" Managing Service Quality, 17(1): 74-91.

Adegbite, O. (2001) "Business Incubators and Small Enterprise Development: The Nigerian Experience" Small Business Economics, 17(3): 157-166.

Aernoudt, R. (2004) "Incubators: Tool for Entrepreneurship?" Small Business Economics, 23(2): 127135.

Albert, P. ve Gaynor, L. (2001) "Incubators - Growing Up, Moving Out, A Review of the Literature", CERAM Sophia Antipolis, December 2001.

Allen, D.N. ve Rahman, S. (1985) "Small Business Incubators: A Positive Environment for Entrepreneurship" Journal of Small Business Management, 23(3): 12-22.

Al-Mubaraki, H.M., A-Karaghouli, W. ve Busler, M. (2010) "The Creation of Business Incubators in Supporting Economic Developments" European Mediterranean and Middle Eastern Conference on Information Systems 2010 (EMCIS2010), Nisan 12-13, Abu Dhabi.

Anavatan, A. (2011) "Zaman Bağımlı Cox Regresyonu: Genç Firmaların Hayatta Kalma Başarısı Üzerine Bir Uygulama” Yayınlanmamış Yüksek Lisans Tezi, Antalya, Akdeniz Üniversitesi Sosyal Bilimler Enstitüsü.

Andersson, U., Forsgren, M. ve Holm, U. (2002) "The Strategic Impact of External Networks: Subsidiary Performance and Competence Development in the Multinational Corporation" Strategic Management Journal, 23(11): 979-996.

Bergek, A. ve Norrman, C. (2008) "Incubator Best Practice: A Framework" Technovation, 28(1-2): 20-28.

Bhabra-Remedios, R.K. ve Cornelius, B. (2003) "Cracks in the Egg: Improving Performance Measures in Business Incubator Research", Small Enterprise Association of Australia and New Zealand 16th Annual Conference, Ekim 28-Ekim 1, Ballarat.

Bianchi, P. ve Bellini, N. (1991) "Public Policies for Local Networks of Innovation" Research Policy, 20(5): 487-497.
Birley, S. (1985) "The Role of Networks in the Entrepreneurial Process" Journal of Business Venturing, 1(1): 107-117.

Bollingtoft, A. ve Ulhoi, J.P. (2005) “The Networked Business Incubator - Leveraging Entrepreneurial Agency?” Journal of Business Venturing, 20(2): 265-290.

Brooks, O. (1986) "Economic Development through Entrepreneurship: Incubators and the Incubation Process" Economic Development Review, 4(2): 24-29.

Brüderl, J. ve Preisendörfer, P. (1998) "Network Support and the Success of Newly Founded Businesses" Small Business Economics, 10(3): 213-225.

Carayannis, E.G. ve Von Zedtwitz, M. (2005) "Architecting GloCal (global-local), Real-Virtual Incubator Networks (G-RVINs) as Catalysts and Accelerators of Entrepreneurship in Transitioning and Developing Economies: Lessons Learned and Best Practices from Current Development and Business Incubation Practices" Technovation, 25(2): 95-110.

Chan, K.F. ve Lau, T. (2005) “Assessing Technology Incubator Programs in the Science Park: The Good, the Bad and the Ugly" Technovation, 25(10): 1215-1228.

Colombo, M.G. ve Delmastro, M. (2002) "How Effective are Technology Incubators? Evidence from Italy" Research Policy, 31(7): 1103-1122.

De Clerq, D. ve Arenius, P. (2006) "The Role of Knowledge in Business Start-up Activity" International Small Business Journal, 24(4): 339-358.

Dean, J., Holmes, S. ve Smith, S. (1997) "Understanding Business Networks: Evidence from the Manufacturing and Service Sectors in Australia" Journal of Small Business Management, 35(1): 78-84.

Demirgil, H. (2008) "Firmaların Hayatta Kalma ve Büyüme Performanslarını Belirleyen Faktörler: Göller Bölgesi Üzerine Bir Araştırma” Yayınlanmamış Doktora Tezi, Isparta, Süleyman Demirel Üniversitesi Sosyal Bilimler Enstitüsü.

Demirgil, H., Karaöz, M., Baptista, R. ve Sungur, O. (2011) "Networking Activities and Growth of Newly Founded Firms Under Incubation”, International Conference on Global Entrepreneurship: The Latest Research on Business Creation, Ekim 6-8, ABD. 
Dyer, J.H., ve Singh, H. (1998) “The Relational View: Cooperative Strategy and Sources of Interorganizational Competitive Advantage" Academy of Management Review, 23(4): 660-679.

Freel, M.S. (2003) "Sectoral Patterns of Small Firm Innovation, Networking and Proximity" Research Policy, 32(5): 751-770.

Freeman, J., Carroll, G.R. ve Hannan, M.T. (1983) "The Liability of Newness: Age Dependence in Organizational Death Rates" American Sociological Review, 48(5): 692-710.

Gartner, W.B. (1985) "A Conceptual Framework for Describing the Phenomenon of New Venture Creation" The Academy of Management Review, 10(4): 696-706.

Gay, B. ve Dousset, B. (2005) "Innovation and Network Structural Dynamics: Study of the Alliance Network of a Major Sector of the Biotechnology Industry" Research Policy, 34(10): 1457-1475.

Göz Çekçeki, Ö. (2007), "Orantılı Hazard Modelinin Zamana Bağlı Değişkenlerle Genişletilmesi ve Çocuk Suçluluğu Üzerine Bir Uygulama”, Yayınlanmamış Yüksek Lisans Tezi, Ankara, Gazi Üniversitesi Fen Bilimleri Enstitüsü.

Granovetter, M. (1985) "Economic Action and Social Structure: The Problem of Embeddedness" American Journal of Sociology, 91(3):481-510.

Grimaldi, R. ve Grandi, A. (2005) "Business Incubators and New Venture Creation: An Assessment of Incubating Models" Technovation, 25(2):111-121.

Gulati, R. (1999) "Network Location and Learning: The Influence of Network Resources and Firm Capabilities on Alliance Formation" Strategic Management Journal, 20(5): 397-420.

Hansen, E.L. (1995) "Entrepreneurial Networks and New Organization Growth" Entrepreneurship Theory and Practice, 19(4): 7-19.

Hansen, M.T., Chesbrough, H.W., Nohria, N. ve Sull, D.N. (2000) "Networked Incubators: Hothouses of the New Economy" Harvard Business Review, 78(5):7484.

Havnes, P. ve Senneseth, K. (2001) "A Panel Study of Firm Growth among SMEs in Networks" Small Business Economics, 16(4): 293-302.

Johannisson, B. (1988) "Business Formation - a Network Approach" Scandinavian Journal of Management, 4(3-4):83-99.

Kajikawa, Y., Takeda, Y., Sakata, I. ve Matsushima, K. (2010) "Multiscale Analysis of Interfirm Networks in Regional Clusters" Technovation, 30(3): 168-180.
Karaöz, M. ve Albeni, M. (2011) "İş Kuluçkalarında Yeni Kurulan Girişimlerin Hayatta Kalma ve Büyüme Performansını Etkileyen Faktörler: KOSGEB İş Geliştirme Merkezleri (İŞGEM) Üzerine bir Araştırma" TÜBİTAK Projesi (No: 109K139) Nihai Rapor, Isparta.

Karaöz, M., Albeni, M. ve Demirgil, H. (2011) "İş Kuluçkalarında Yeni Kurulan Girişimlerin Hayatta Kalmalarını Etkileyen Faktörler" Finans Politik ve Ekonomik Yorumlar Dergisi, 48(557): 59-84.

Kleinbaum, D.G. ve Klein, M. (2005) Survival Analysis: A Self-Learning Text, 2nd Edition, New York, Springer.

KOSGEB (2010) "Girişimcilik Destek Programı Uygulama Esasları”, UE-03/00.

Köseoğlu, G. (2007) "Social Capital Development among Tenant Firms and Between Tenant Firms and the Host University in Business Incubators: a Case of a Turkish Business Incubator", Yayınlanmamış Yüksek Lisans Tezi, Ankara, ODTÜ.

Larson, A. ve Starr, J.A. (1993) "A Network Model of Organization Formation" Entrepreneurship Theory and Practice, 17(2): 5-15.

Lumpkin, J.R. ve Ireland, R.D. (1988) "Screening Practices of New Business Incubators: The Evaluation of Critical Success Factors" American Journal of Small Business, 12(4): 59-81.

McAdam, M. ve Marlow, S. (2007) "Building Futures of Stealing Secrets?: Entrepreneurial Cooperation and Conflict within Business Incubators" International Small Business Journal, 25(4): 361-382.

McAdam, M. ve Marlow, S. (2008) "A Preliminary Investigation into Networking Activities within the University Incubator" International Journal of Entrepreneurial Behaviour and Research, 14(4): 219-241.

McAdam, M., Galbraith, B., McAdam, R. ve Humphreys, P. (2006) "Business Processes and Networks in University Incubators: A Review and Research Agendas" Technology Analysis and Strategic Management, 18(5): 451-472.

Ostgaard, T.A. ve Birley, S. (1996) "New Venture Growth and Personal Networks" Journal of Business Research, 36(1): 37-50.

Owen-Smith, J., Riccaboni, M., Pammolli, F. ve Powell, W.W. (2002) "A Comparison of U. S. and European University-Industry Relations in the Life Sciences" Management Science, 48(1): 24-43.

Özbek, Z. (2008) “KOBİ'lerin Türk Ekonomisine Etkileri” Uluslararası Ekonomik Sorunlar Dergisi, 31: 4957. 
Peters, L., Rice, M. ve Sundararajan, M. (2004) "The Role of Incubators in the Entrepreneurial Process" Journal of Technology Transfer, 29(1): 83-91.

Phan, P.H., Siegel, D.S. ve Wright, M. (2005) "Science Parks and Incubators: Observations, Synthesis and Future Research" Journal of Business Venturing, 20(2): 165-182.

Powell, W., Koput, K. ve Smith-Doerr, L. (1996) "Interorganizational Collaboration and the Locus of Innovation: Networks of Learning in Biotechnology" Administrative Science Quarterly, 41(1): 116-145.

Powell, W., White, D., Koput, K. ve Owen-Smith, J. (2005) "Network Dynamics and Field Evolution: The Growth of Interorganizational Collaboration in the Life Sciences" American Journal of Sociology, 110(4): 11321205.

Riccaboni, M. ve Pammolli, M. (2002) "On Firm Growth in Networks" Research Policy, 31(8-9): 14051416.

Rothaermel, F.T. (2001) "Complementary Assets, Strategic Alliances, and the Incumbent's Advantage: An Empirical Study of Industry and Firm Effects in the Biopharmaceutical Industry" Research Policy, 30(8): 1235-1251.

Rothaermel, F.T. ve Thursby, M. (2005) "Incubator Firm Failure or Graduation? The Role of University Linkages" Research Policy, 34(7): 1076-1090.

Rothschild, L. ve Darr, A. (2005) "Technological Incubators and the Social Construction of Innovation Networks: An Israeli Case Study" Technovation, 25(1): 59-67.

Schwartz, M. ve Hornych, C. (2010) "Cooperation Patterns of Incubator Firms and the Impact of Incubator Specialization: Empirical Evidence from Germany" Technovation, 30(9): 485-495.

Scillitoe, J.L. ve Chakrabarti, A.K. (2010) "The Role of Incubator Interactions in Assisting New Ventures" Technovation, 30(3): 155-167.

Shahidi, H. (1998) "The Impact of Business Incubators in Entrepreneurial Networking: A Comparative Study of Small, High-Technology Firms" Yayınlanmamış Doktora Tezi, ABD, George Washington University.

Sherman, H.D. (1999) "Assessing the Intervention Effectiveness of Business Incubation Programs on New Business Start-Ups" Journal of Developmental Entrepreneurship, 4(2): 117-133.

Smilor, R.W. (1987) "Commercializing Technology through New Business Incubators" Research Management, 30(5): 36-41.
Stinchcombe, A.L. (1965) "Social Structures and Organizations" March, J.G. (ed), Handbook of Organizations, Chicago, Rand McNally, 142-193.

Suk, J.Y. ve Mooweon, R. (2006) "Resource Mobilization and Business Incubation: The Case of Korean Incubators" Development and Society, 35(1): 2946.

Sungur, O. (2007) "Bölgesel Ölçekte İnovasyon: NUTS 2 TR61 Düzeyi KOBİ'leri ile Yerel Paydaşların Bilgi Dinamikleri ve Ağbağları Üzerine Bir İnceleme", Yayınlanmamış Yüksek Lisans Tezi, Isparta, Süleyman Demirel Üniversitesi Sosyal Bilimler Enstitüsü.

Tötterman, H. ve Sten, J. (2005) "Start-ups, Business Incubation and Social Capital" International Small Business Journal, 23(5): 487-511.

UN - United Nations (2009) "Regional Profile of the Information Society in Western Asia" Economic and Social Commission for Western Asia, New York.

Uzzi, B. (1996) "The Sources and Consequences of Embeddedness for the Economic Performance of Organizations: The Network Effect" American Sociological Review, 61(4): 674-698.

Verma, S. (2004) "Success Factors for Business Incubators: An Empirical Study on Canadian Business Incubators" Yayınlanmamış Yüksek Lisans Tezi, Kanada, Carleton University.

Winger, A. (2000) "Stimulating the Supply and Building the Capacity of New Schools and School Developers", Recommendations for the Design and Implementation of a New Schools Incubator, Center on Reinventing Public Education, ABD.

Yeung, H.W. (1994) "Critical Reviews of Geographical Perspectives on Business Organisations and the Organisation of Production: Towards a Network Approach" Progress in Human Geography, 18(4): 460-490.

Yu, J., Middleton, M. ve Jackson, R. (2009) "Toward the Geography of Business Incubator Formation in the United States" 56th North American Regional Science Association International (RSAI) Conference, Kasım 1821, ABD.

Zaheer, A. ve Bell, G.G. (2005) "Benefiting from Network Position: Firm Capabilities, Structural Holes and Performance" Strategic Management Journal, 26(9): 809-825.

Zhang, M. ve Jiang, R. (2009) "Empirical Research on Business Incubation Networking Operation and the Incubation Performance" International Conference on Information Management, Innovation Management and Industrial Engineering (ICIII 2009), Aralık 26-27, Çin, 267-270.

Zhao, L. ve Aram, J.D. (1995) "Networking and Growth of Young Technology-Intensive Ventures in China" Journal of Business Venturing, 10(5): 349-370. 
